\title{
Changes and significance of hydrodynamic parameters in Budd-Chiari syndrome with obstruction of the inferior vena cava prior to and after interventional therapy
}

\author{
LULU LYU ${ }^{1,2^{*}}$, PENG XU $^{3 *}, \mathrm{JIE} \mathrm{PING}^{3}$, CHUNFENG $\mathrm{HU}^{3}$ and $\mathrm{KAI} \mathrm{XU}^{1,3}$ \\ ${ }^{1}$ The First School of Clinical Medicine, Nanjing Medical University, Nanjing, Jiangsu 210029; \\ ${ }^{2}$ Department of CT and MRI, Xuzhou Central Hospital, Xuzhou, Jiangsu 221009; ${ }^{3}$ Department of Radiology, \\ Affiliated Hospital of Xuzhou Medical University, Xuzhou, Jiangsu 221002, P.R. China
}

Received December 4, 2019; Accepted April 17, 2020

DOI: 10.3892/etm.2021.9609

\begin{abstract}
In recent years, the role of computational fluid dynamics for Budd-Chiari syndrome evaluation has become the focus of certain studies. The purpose of the present study was to evaluate the role of computational fluid dynamics in Budd-Chiari syndrome with obstruction of the inferior vena cava (IVC). Magnetic resonance venous angiography was used to obtain original IVC and hepatic venous blood flow images from patients with Budd-Chiari syndrome. The computational fluid dynamics method was used to establish a three-dimensional model and simulate the blood flow velocity, wall shear stress and wall pressure. The results revealed that the hemodynamic parameters of Budd-Chiari syndrome were successfully simulated by computational fluid dynamics. The hemodynamic parameters of the IVC stenosis varied with the cardiac cycle. Vascular flow velocity (pre-operative, $1.64 \pm 0.10 \mathrm{~m} / \mathrm{sec}$; post-operative, $0.34 \pm 0.14 \mathrm{~m} / \mathrm{sec} ; \mathrm{t}=34.97$, $\mathrm{P}<0.001$ ) and wall shear stress (pre-operative, 25.69 $\pm 2.85 \mathrm{~Pa}$; post-operative, $3.51 \pm 1.70 \mathrm{~Pa} ; \mathrm{t}=29.86, \mathrm{P}<0.001)$ at the area of stenosis decreased after interventional therapy and the wall pressure increased (pre-operative, $-119.33 \pm 251.50 \mathrm{~Pa}$; post-operative, $1,128.42 \pm 207.70 \mathrm{~Pa} ; \mathrm{t}=17.10, \mathrm{P}<0.001)$. In conclusion, the computational fluid dynamics method was able to effectively simulate the hemodynamic parameters of Budd-Chiari syndrome with obstruction of the IVC and may provide an effective quantitative method for the evaluation of vascular function post-treatment.
\end{abstract}

Correspondence to: Dr Kai Xu, The First School of Clinical Medicine, Nanjing Medical University, 300 Guangzhou Road, Nanjing, Jiangsu 210029, P.R. China

E-mail: xuk_xuzhou@126.com

*Contributed equally

Key words: Budd-Chiari syndrome, hemodynamics, inferior vena cava, finite element

\section{Introduction}

Budd-Chiari syndrome (BCS) is a pathological condition associated with obstruction of the hepatic veins (HVs) and/or the inferior vena cava (IVC) above its opening (1). Percutaneous transluminal angioplasty is a relatively effective treatment but relapse after surgery is common; therefore, it is important to determine the mechanism underlying the development of BCS and evaluate interventional efficacy $(2,3)$. Previous studies have demonstrated that hemodynamic changes are crucial for the occurrence of cardiovascular system-associated diseases but currently available research has mostly been limited to the arterial vasculature, including cerebral arteries, carotid arteries, and thoracic and abdominal aorta (4-6). Research on the diseases of the IVC is still in its early stages. In the present study, a patient with BCS with obstruction of the IVC was selected and the computational fluid dynamics (CFD) technique was used to evaluate the changes in blood flow velocity, wall pressure and wall shear stress prior to and after interventional treatment. Based on previous research, a combination of semi-quantitative and quantitative indicators was used to analyze the hydrodynamic parameters of the IVC (7). The aim of the present study was to provide a novel quantitative method to further elucidate the hemodynamic changes and possible mechanisms underlying IVC obstruction in BCS prior to and after interventional therapy.

\section{Materials and methods}

Study subject. A female 64-year-old patient with BCS and IVC obstruction was selected as the study subject. The patient was admitted to the Affiliated Hospital of Xuzhou Medical University (Xuzhou, China) due to abdominal distension and wheezing. The patient had signed an informed consent form prior to treatment and consent for publication was also obtained from the patient. The present study was approved by the Institutional Review Board of Affiliated Hospital of Xuzhou Medical University.

MRI data acquisition. MR venography was performed with a 3.0-T clinical unit (Discovery 750w; GE Healthcare) along 
with a 32-element phased-array coil. Dynamic LAVA MR sequences were performed prior to and after the administration of the contrast agent (gadopentetate dimeglumine) during three different phases: Hepatic arterial phase (25 sec after contrast agent administration), portal venous phase (60 sec after contrast agent administration) and equilibrium phase (150 sec after contrast agent administration). The parameters for the LAVA sequence were as follows: Matrix, 288x256; flip angle, $12^{\circ}$; bandwidth, 83.33 ; field of view, $40 \mathrm{~cm}$; layer thickness, $0.8 \mathrm{~mm}$.

Interventional therapy. A GE 3100 digital subtraction angiography machine (GE Healthcare) and the Seldinger puncture technique were used for endovascular interventional therapy. The stenosis of IVC was pre-dilated with a small balloon catheter (Cook Medical Inc.) and then dilated repeatedly with a large balloon (Cook Medical Inc.).

Vascular modeling. The 3-dimensional (3D) image was reconstructed by Simpleware software using MR venography images and the model was smoothed and meshed by intercepting the target blood vessels. Subsequently, the files were imported into the Fluent 17.0 software (ANSYS, Inc.) to establish an individualized model of the IVC. The IVC model included the IVC and HVs. The blood flow in the lumen was modeled as a homogeneous and incompressible Newtonian fluid, the dynamic blood viscosity was $0.0035 \mathrm{P}$ and the mass density was $1,050 \mathrm{~kg} / \mathrm{m}^{3}$. It was hypothesized that the vessel wall was rigid and the velocity on the wall was set to $0 \mathrm{~m} / \mathrm{sec}$. The continuity equation of flow mass conservation and the Navier-Stokes equation of momentum conservation were adopted (8). The heart rate was assumed to be $85 / \mathrm{min}$ and the cardiac cycle $0.7 \mathrm{sec}$. The entire calculation process started from the static flow field with a time step of $0.035 \mathrm{sec}$. The maximum number of iterations per time step was 2,000 and the time step was 20 steps. Fluent software was used to output the maximum and minimum hemodynamic simulation values of blood flow velocity, wall shear stress and wall pressure prior to and after interventional therapy in one cardiac cycle. The mass flow rate was all set at $0.1 \mathrm{~m} / \mathrm{sec}$ at the inlets and the blood pressure at the exit was set to $0 \mathrm{~Pa}$.

Statistical analysis. All statistical analyses were performed using GraphPad Prism software (version 5.0; GraphPad Software, Inc.). The hemodynamic parameters (blood flow velocity, wall shear stress and wall pressure) of 20 nodes in a complete cardiac cycle at the narrowest point of the IVC were measured and their mean values ( \pm standard deviation) were calculated. The parameters prior to and after interventional therapy were compared using a paired-samples t-test. $\mathrm{P}<0.01$ was considered to indicate a statistically significant difference.

\section{Results}

General characteristics of the model. The pre-operative IVC 3D model included 17,482 finite element model units and 49,533 nodes. The total number of finite element model units after interventional therapy was 17,542 and the total number of nodes was 50,372. According to the model, the diameter and shape of the IVC after balloon dilatation were restored to approximately normal levels (Fig. 1).

Analysis of blood flow velocity. Pre-operative blood flow velocity was measured in the midline region of the IVC, where stenosis was the most prominent. The maximum value in the cardiac cycle was $1.85 \mathrm{~m} / \mathrm{sec}$, the minimum value was $1.53 \mathrm{~m} / \mathrm{sec}$ and the mean value was $1.64 \pm 0.10 \mathrm{~m} / \mathrm{sec}$. The flow velocity in the upper and lower regions was relatively reduced (Fig. 2A and B). After treatment, the maximum value of blood flow velocity in the original stenosis of the IVC was $0.48 \mathrm{~m} / \mathrm{sec}$, the minimum value was $0.06 \mathrm{~m} / \mathrm{sec}$ and the mean value was $0.34 \pm 0.14 \mathrm{~m} / \mathrm{sec}$. The post-operative flow velocity distribution characteristics were similar to those prior to treatment, i.e., the maxima region was still distributed in the central line area of the IVC and the blood flow velocity in the adjacent region was slightly lower (Fig. 2C and D).

Analysis of wall shear stress. Prior to the operation, the shear stress of the IVC wall increased significantly in the stenotic area and it was relatively uniform in the non-stenotic area. The maximum and minimum values of wall shear stress in the stenotic area were 29.71 and $21.37 \mathrm{~Pa}$ in the cardiac cycle, with a mean of $25.69 \pm 2.85 \mathrm{~Pa}$ (Fig. $3 \mathrm{~A}$ and $\mathrm{B}$ ). The maximum and minimum wall shear stress were 6.12 and $0.53 \mathrm{~Pa}$ in the original stenotic area after treatment, with a mean value of $3.51 \pm 1.70 \mathrm{~Pa}$. However, the wall shear stress in the stenotic part of the cardiac cycle was still higher compared with that in the non-stenotic part (Fig. 3C and D).

Analysis of wall pressure. The wall pressure of the distal end of the IVC was significantly increased prior to the operation. The wall pressure gradually decreased in the stenotic and proximal end of the IVC, particularly in the narrowest part of the lumen during the cardiac cycle (Fig. 4A and B). The maximum and minimum wall pressure in the narrowest area prior to the operation were 290.32 and $-464.21 \mathrm{~Pa}$, with a mean of $-119.33 \pm 251.50 \mathrm{~Pa}$ in the cardiac cycle. The wall pressure of the distal end of the IVC decreased significantly after interventional therapy (Fig. 4C and D). The maximum and minimum values in the narrowest part were $1,431.23$ and $850.68 \mathrm{~Pa}$ in the cardiac cycle, with a mean of $1,128.42 \pm 207.70 \mathrm{~Pa}$.

Following treatment, the blood flow velocity and wall shear stress all decreased significantly in the narrowest part of the lumen ( $\mathrm{t}=34.97$ and 29.86; $\mathrm{P}<0.001$; Fig. 5A and $\mathrm{B})$. However, the wall pressure increased remarkably in the lesion area after interventional therapy ( $\mathrm{t}=17.10, \mathrm{P}<0.001$; Fig. 5C).

\section{Discussion}

In recent years, CFD technology has been widely used in biomedical research (9-11). This technology may be used to calculate important functional indicators, including target vessel wall pressure, wall shear stress and blood flow velocity. The application of CFD in the cerebral artery has been well established, particularly for the evaluation of risk factors for aneurysm rupture and the efficacy of stent surgery, which has important clinical significance (12). At present, the morphological and functional assessment of IVC in BCS mainly includes ultrasound, CT, MRI and digital subtraction angiography 
A

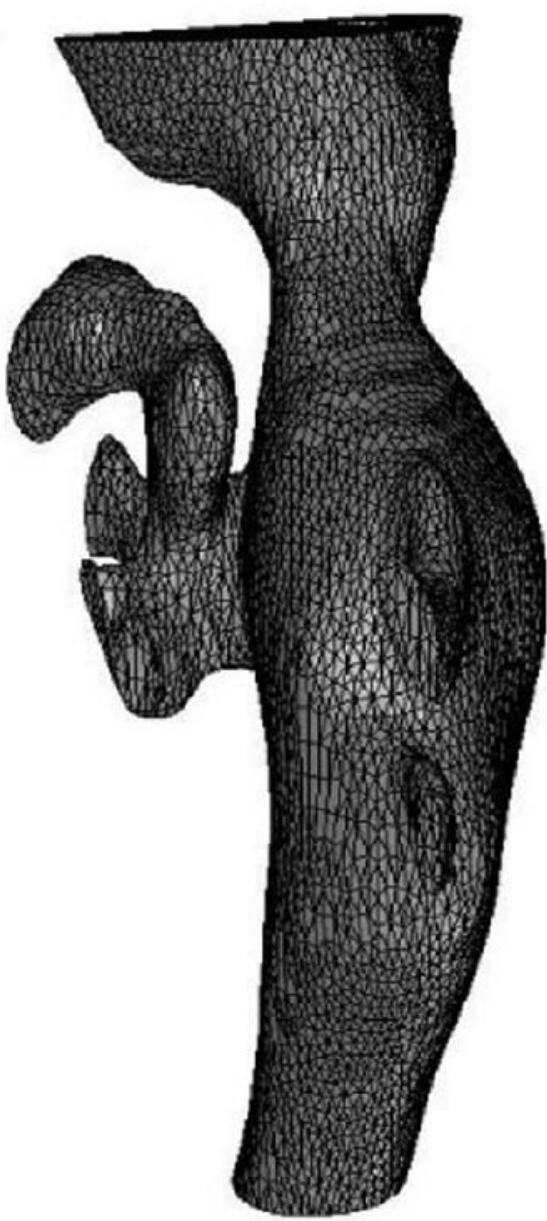

B

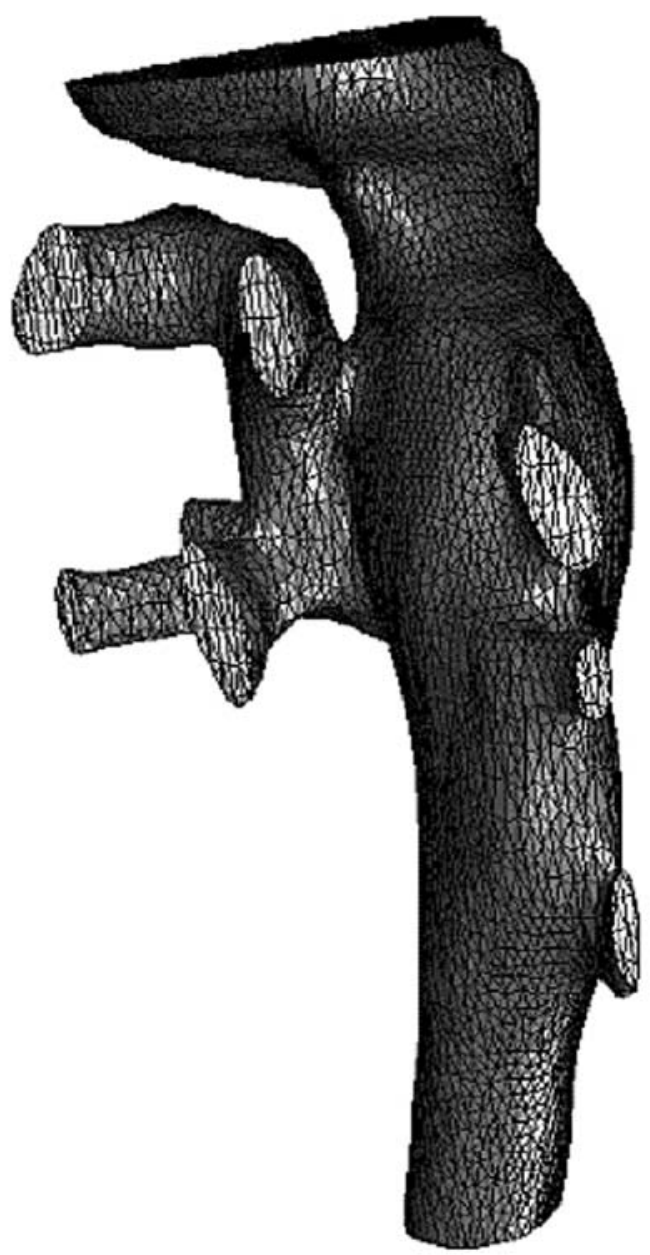

Figure 1. Grid model of the IVC. (A) Posterior stenotic segment of the IVC prior to treatment. (B) The diameter and shape of the original stenotic area after interventional therapy resembled those of the normal IVC. IVC, inferior vena cava.

(DSA) (13-15). Among these, CT and MRI are able to evaluate the shape of stenotic vessels, but it is difficult to perform a functional evaluation. Ultrasound may achieve morphological and functional evaluation but the subjective factors of the operator confer a somewhat poor repeatability. DSA may be used to evaluate blood flow in the lumen of the lesion, but it is difficult to observe the shape of the blood vessels and wall structure (16). CFD technology has enabled a better analysis of the morphology and function of the IVC in patients with BCS.

Previous studies have used CFD to evaluate the IVC in BCS: Certain scholars have used CFD technology to construct a three-dimensional model of IVC occlusion and clarify the distribution of local blood flow velocity and shear stress on the wall of the IVC, and have proposed that this may be the cause of thickening and thrombosis of the IVC in patients with BCS (17). By analyzing the changes in the blood flow parameters prior to and after BCS interventional therapy, Nai et al (18) pointed out that the wall shear force remained higher compared with that of the normal IVC in patients with BCS, which may be one of the reasons for restenosis after BCS interventional therapy. Cheng et al (7) constructed a BCS vascular model based on MRI and idealized membranes with different degree of stenosis (16, 37 and 54\%) were built based on the vascular model of BDS. CFD technology was used to successfully analyze the blood flow parameters in the lesion area, and the difference of wall shear force in different degrees of stenosis was demonstrated. In the present study, the time factor of the cardiac cycle was added to the basis provided by previous studies. Quantitative parameters of vascular stenosis in the cardiac cycle were obtained, and the parameters prior to and after the operation were compared and analyzed, in the hope that this may enable a more objective analysis of the changes in the vascular parameters in the lesion area of BCS and the fluid parameters following interventional therapy.

The experimental results demonstrated that the blood flow velocity and wall shear stress were highest and the wall pressure was lowest in the IVC stenosis prior to the intervention. The results were consistent with those reported by a previous study (18). According to the incompressible fluid continuity equation, $\mathrm{Q}=\mathrm{V} 1 \times \mathrm{A} 1=\mathrm{V} 2 \times \mathrm{A} 2$, where $\mathrm{V}$ indicates the mean flow velocity of the section and A the cross-sectional area of the flow, for any two flow cross-sections, $\mathrm{V}$ is inversely proportional to A when the total flow is constant. When blood flows through the stenotic area of the IVC, V markedly increases due to a sharp decrease in $\mathrm{A}$. After the intervention, the $\mathrm{V}$ value decreased due to the increase of the $\mathrm{A}$ in the narrowed area.

According to the Bernoulli principle (19), $p+1 / 2 \rho v^{2}+\rho g h=C$, where $p$ is the pressure at a point in the fluid, $v$ is the velocity at that point, $\rho$ is the fluid density, $g$ is the gravitational acceleration, $h$ is the height of the point and 
A
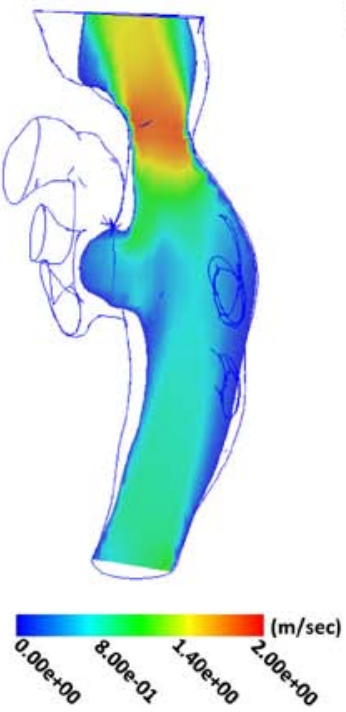

B

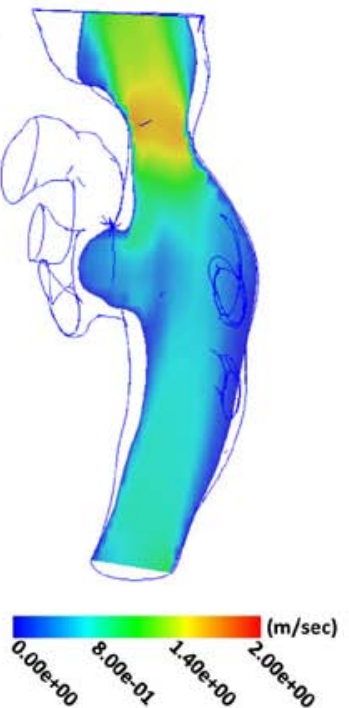

C
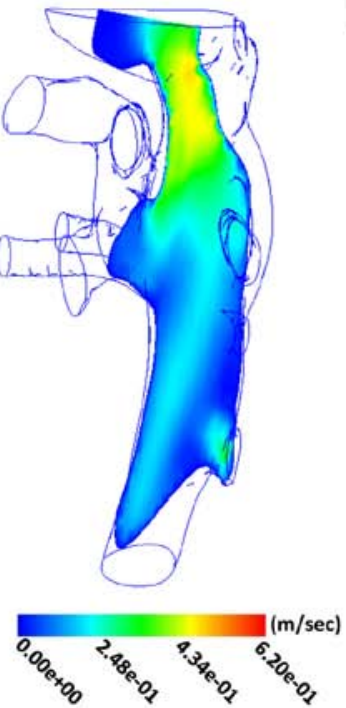

D

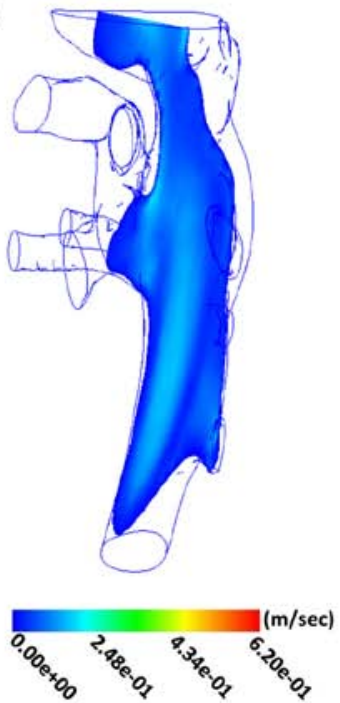

Figure 2. Distribution of blood flow velocity in the lumen of the IVC. The (A) maximal and (B) minimal phase of blood flow velocity prior to the operation in the IVC. The (C) maximal and (D) minimal phase of blood flow velocity after the operation in the IVC. IVC, inferior vena cava.

\section{A}
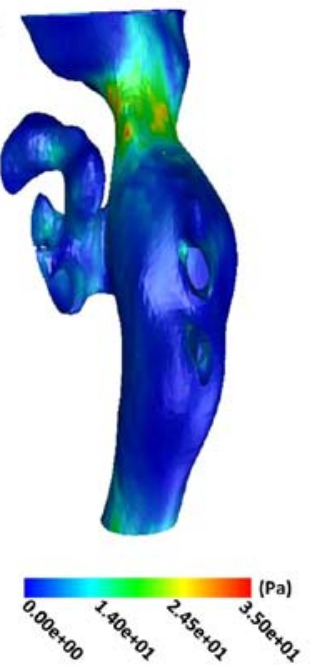

B
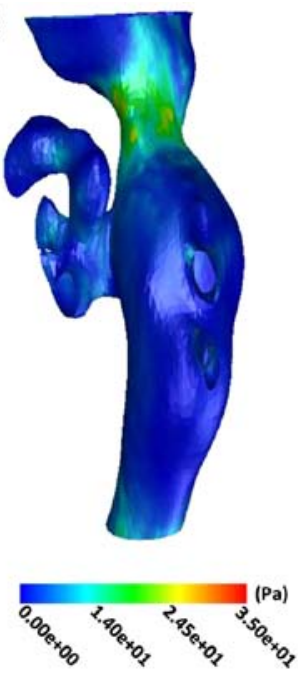

$\mathrm{C}$
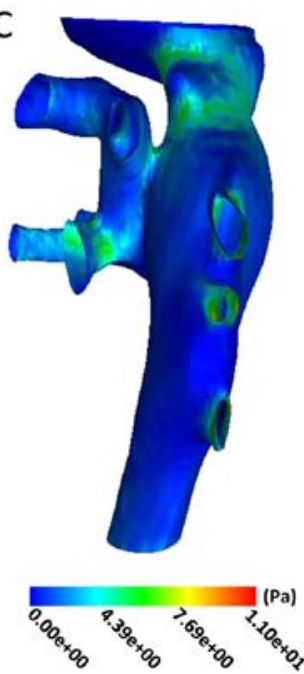

D
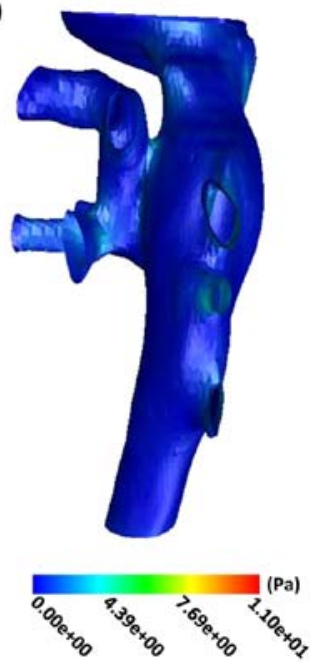

Figure 3. Distribution of wall shear stress in IVC. The (A) maximal and (B) minimal phase of wall shear stress prior to the operation in the IVC. The (C) maximal and (D) minimal phase of wall shear stress after the operation in the IVC. IVC, inferior vena cava.

$\mathrm{C}$ is a constant, when the blood flow is at a high flow rate, a higher flow rate is associated with a smaller pressure. Prior to treatment, the blood flow velocity through the stenotic area was higher, which reduced the pressure on the blood vessel wall. Therefore, the stenotic area of IVC would have a negative value, i.e., a 'negative pressure' state. As the flow rate at the stenosis decreased after treatment, the corresponding wall pressure increased.

The shear stress is obtained by the Hagen-Poiseuille formula (20): $F=4 \eta Q / \pi R^{3}$, where $F$ is the shear stress, $\eta$ is the fluid viscosity, $\mathrm{Q}$ is the flow rate and $\mathrm{R}$ is the lumen radius. The shear stress is a force that obstructs the blood flow parallel to the axis of the blood vessel. Its mechanism is that blood viscosity causes friction between the blood and the vessel wall, which is opposite to the direction of blood flow (21). A commonly used unit for describing the shear force of a blood vessel wall is Dyne $/ \mathrm{cm}^{2}$ (1 Dyne $\left./ \mathrm{cm}^{2}=0.1 \mathrm{~Pa}\right)$. It was previously reported that the vascular endothelial cell basement membrane may become exposed due to direct mechanical damage in the presence of excessive wall shear forces $\left(>100\right.$ Dyne $\left./ \mathrm{cm}^{2}\right)$, resulting in endogenous coagulation followed by vascular occlusion (20). In the present study, the mean wall shear force of the stenotic area pre-operatively was $25.69 \mathrm{~Pa}>100 \mathrm{Dyne} / \mathrm{cm}^{2}$, and this excessive wall shear force may be one of the causes of IVC stenosis in BCS. The mean value of wall shear stress in the original stenotic area was $3.51 \mathrm{~Pa}\left(35.1\right.$ Dyne $\left./ \mathrm{cm}^{2}\right)$. This value was significantly lower compared with that prior to treatment and had then returned to the physiological high shear force range (15-50 Dyne $/ \mathrm{cm}^{2}$ ). The physiological high shear force enables timely endothelial cell repair and intimal hyperplasia is suppressed, which may promote benign remodeling based on vasodilation $(20,22)$. Therefore, the evaluation of the shear force changes of the IVC wall in BCS may help elucidate the cause of vascular stenosis and also provides quantitative indicators and theoretical support 
A
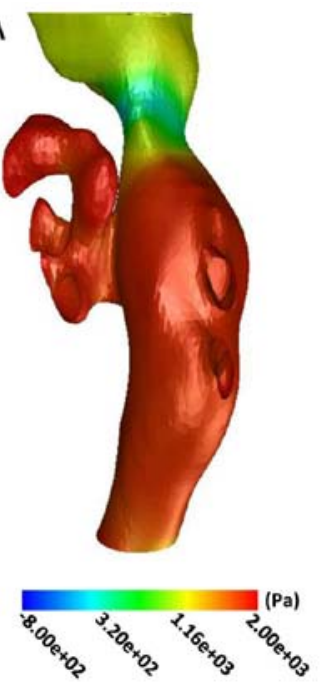

B

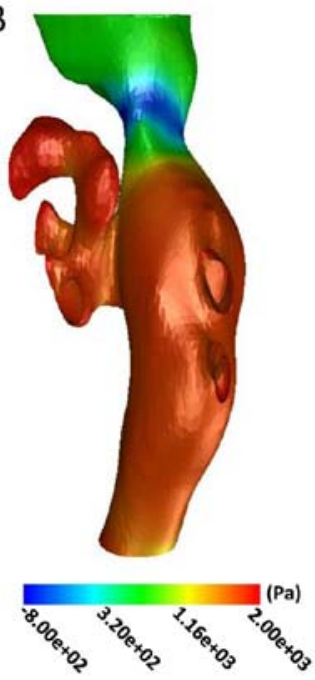

C

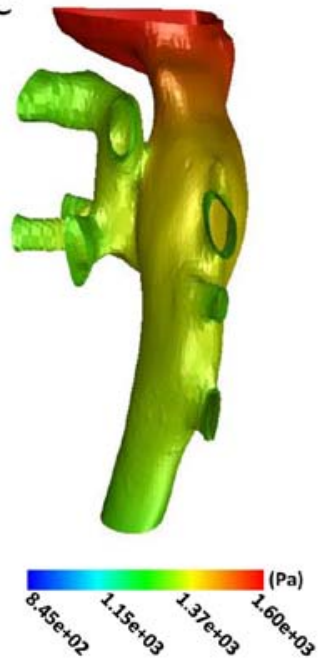

D

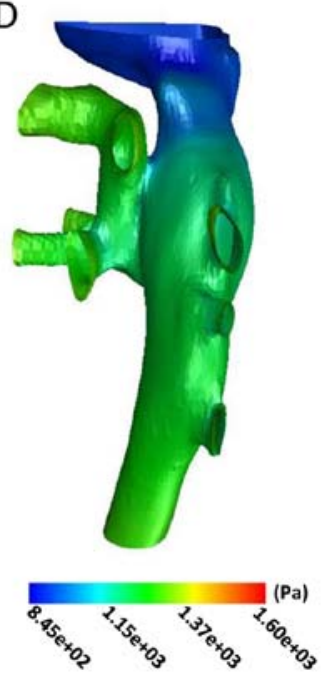

Figure 4. Distribution of wall pressure in the IVC. The (A) maximal and (B) minimal phase of wall pressure prior to the operation in the IVC. The (C) maximal and (D) minimal phase of wall pressure after the operation in the IVC. IVC, inferior vena cava.

A

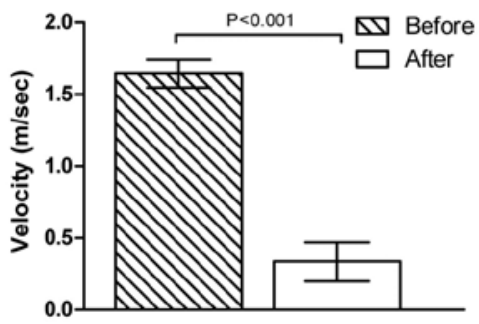

B

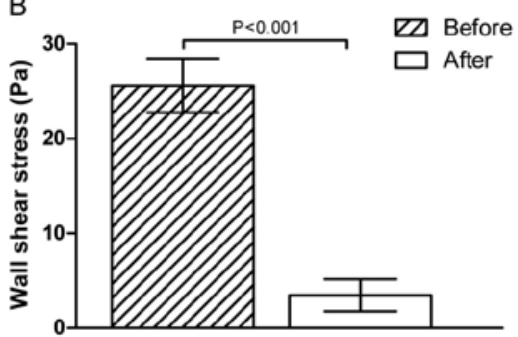

C

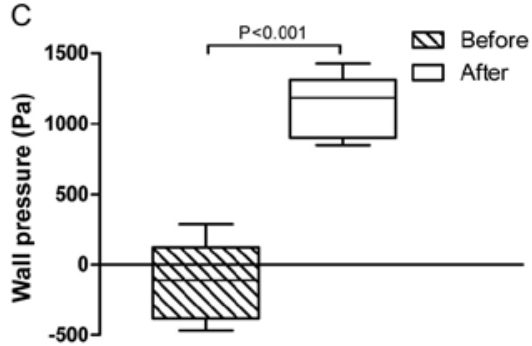

Figure 5. Distribution and changes of hemodynamic parameters in the lesion area of the inferior vena cava prior to and after interventional therapy: (A) Blood flow velocity, (B) wall shear stress and (C) wall pressure.

for the evaluation of interventional therapy and post-operative follow-up. In addition, under physiological conditions, the blood flow in the circulatory system periodically changes with the cardiac cycle, which is referred to as pulsating flow $(23,24)$.

Based on previous studies on IVC, the time factor was added to the model. The results demonstrated that the blood flow velocity, wall pressure and wall shear stress change periodically with the cardiac cycle, which may prove helpful in establishing a three-dimensional model of IVC occlusion in BCS in the real circulatory state that is more in line with human hemodynamics in the future.

Although the model of IVC stenosis in BCS was successfully established in the present study, there were certain limitations. First, the human vascular wall is characterized by elasticity but in the present study, the vascular wall was considered as a rigid structure, which is different from the real blood flow environment. Furthermore, the extent and degree of venous stenosis, the complexity of collateral circulation and the individual differences of venous vascular lesions caused by BCS will affect the repeatability of modeling to a certain extent.

In conclusion, the present study successfully established a model of IVC stenosis based on BCS through CFD. The hemodynamic characteristics of blood flow velocity, wall shear stress and wall pressure in the lesion area in association with the cardiac cycle were obtained, which may provide a new possibility for the clinical evaluation of IVC in BCS.

\section{Acknowledgements}

Not applicable.

\section{Funding}

The present study was supported by grants from the Clinical Medical Science and Technology Project of Jiangsu Province (grant no. BE2017637), Key Research and Development Plan of Xuzhou City (grantno. KC20111) and the Medical Innovation Team (leading talent) of Jiangsu Province (grant no. CXTDA2017028).

\section{Availability of data and materials}

All data generated during this study are included in this published article.

\section{Authors' contributions}

LL designed the experiments and drafted the manuscript. PX and JP performed the experiments and analyzed data. $\mathrm{CH}$ conducted statistical analysis, data interpretation and revised the manuscript. KX designed the study, interpreted data, provided administrative support and study supervision, and, additionally, conducted critical revision and final approval of the manuscript. All authors read and approved the final manuscript. 


\section{Ethics approval and consent to participate}

All patients provided written informed consent prior to treatment. The present study was approved by the Institutional Review Board of Affiliated Hospital of Xuzhou Medical University.

\section{Patient consent for publication}

All patients provided written informed consent for publication.

\section{Competing interests}

The authors declare that they have no competing interests.

\section{References}

1. Copelan A, Remer EM, Sands M, Nghiem H and Kapoor B: Diagnosis and management of Budd Chiari syndrome: An update. Cardiovasc Intervent Radiol 38: 1-12, 2015.

2. Huang Q, Shen B, Zhang Q, Xu H, Zu M, Gu Y, Wei N, Cui Y and Huang R: Comparison of long-term outcomes of endovascular management for membranous and segmental inferior vena cava obstruction in patients with primary Budd-Chiari syndrome. Circ Cardiovasc Interv 9: e003104, 2016.

3. Mukund A, Pargewar SS, Desai SN, Rajesh S and Sarin SK: Changes in liver congestion in patients with Budd-Chiar syndrome following endovascular interventions: Assessment with transient elastography. J Vasc Interv Radiol 28: 683-687, 2017.

4. Fukazawa K, Ishida F, Umeda Y, Miura Y, Shimosaka S, Matsushima S, Taki W and Suzuki H: Using computational fluid dynamics analysis to characterize local hemodynamic features of middle cerebral artery aneurysm rupture points. World Neurosurg 83: 80-86, 2015.

5. Numata S, Itatani K, Kanda K, Doi K, Yamazaki S, Morimoto K, Manabe K, Ikemoto K and Yaku H: Blood flow analysis of the aortic arch using computational fluid dynamics. Eur J Cardiothorac Surg 49: 1578-1585, 2016.

6. Gharahi H, Zambrano BA, Zhu DC, DeMarco JK and Baek S: Computational fluid dynamic simulation of human carotid artery bifurcation based on anatomy and volumetric blood flow rate measured with magnetic resonance imaging. Int J Adv Eng Sci Appl Math 8: 46-60, 2016.

7. Cheng D, Zhuang Y, Kou Q, Zhang M, Zhao Y, Han C, Li J, Wang Y, Xu K, Mo F and Zhang J: Numerical simulation of hemodynamics in membranous obstruction of the suprahepatic inferior vena cava based on a subject-specific Budd-Chiari syndrome model. Clin Biomech (Bristol, Avon) 52: 20-24, 2018.

8. Khalafvand SS, Ng EY, Zhong L and Hung TK: Three-dimensional diastolic blood flow in the left ventricle. J Biomech 50: 71-76, 2017.

9. Katritsis DG, Theodorakakos A, Pantos I, Andriotis A, Efstathopoulos EP, Siontis G, Karcanias N, Redwood S and Gavaises M: Vortex formation and recirculation zones in left anterior descending artery stenoses: Computational fluid dynamics analysis. Phys Med Biol 55: 1395-1411, 2010.
10. Choi G, Lee JM, Kim HJ, Park JB, Sankaran S, Otake H, Doh JH, Nam CW, Shin ES, Taylor CA and Koo BK: Coronary artery axial plaque stress and its relationship with lesion geometry: Application of computational fluid dynamics to coronary CT angiography. JACC Cardiovasc Imaging 8: 1156-1166, 2015.

11. Yeri A and Shah RV: Comparison of computational fluid dynamics and machine learning-based fractional flow reserve in coronary artery disease. Circ Cardiovasc Imaging 11: e007950, 2018.

12. Munarriz PM, Gómez PA, Paredes I, Castaño-Leon AM, Cepeda S and Lagares A: Basic principles of hemodynamics and cerebral aneurysms. World Neurosurg 88: 311-319, 2016.

13. Xu K, Ren K and Chen YS: Application and evaluation of non-invasive imaging examination of Budd-Chiari syndrome. Chin Med J (Engl) 120: 91-94, 2007.

14. Faraoun SA, Boudjella Mel A, Debzi N, Afredj N, Guerrache Y, Benidir N, Bouzid C, Bentabak K, Soyer P and Bendib SE: Budd-Chiari syndrome: A prospective analysis of hepatic vein obstruction on ultrasonography, multidetector-row computed tomography and MR imaging. Abdom Imaging 40: 1500-1509, 2015.

15. Wang HW, Shi HN, Cheng J, Xie F, Luo YK and Tang J: Real-time shear wave elastography (SWE) assessment of short-and long-term treatment outcome in Budd-Chiari syndrome: A pilot study. PLoS One 13: e0197550, 2018.

16. Van Wettere M, Bruno O, Rautou PE, Vilgrain V and Ronot M: Diagnosis of Budd-Chiari syndrome. Abdom Radiol (NY) 43: 1896-1907, 2018

17. Sun C, Zhao Y, Ping J and Cui Y: Numerical simulation analysis of hemodynamic values of Budd-Chiari syndrome based on MR image. J Med Postgra 27: 1297-1300, 2014.

18. Nai Q, Ping J, Xu W, Xu H, Wei M and Zhang W: Analysis of simulated hemodynamic parameters of Budd-Chiari syndrome with perforated membrane of inferior vena cava before and after interventional therapy. Chin J Hepatobiliary Surg 22: 734-737, 2016.

19. Yu H, Yan H and Jiang Y: Discussions on Bernoulli Equations. Insight-Mechanics 1: 12-16, 2018.

20. Xu Y and Zhang L: Changes in shear force after autologous arteriovenous fistula establishment. Natl Med J China 95: 3473-3475, 2015 (In Chinese).

21. Van Tricht I, De Wachter D, Tordoir J and Verdonck P: Hemodynamics and complications encountered with arteriovenous fistulas and grafts as vascular access for hemodialysis: A review. Ann Biomed Eng 33: 1142-1157, 2005.

22. Cao X, Dong G and Yang S: Influence of shear stress on vascular endothelial function and its mechanism. J Chin Pract Diagn Ther 30: 956-958, 2016 (In Chinese).

23. Liu Z, Teng Z and Tan K: Stress distribution on arterial wall under pulsatile flow. Chin J Theor Appl Mech 34: 696-704, 2002 (In Chinese).

24. Lin Y, Jing Z, Zhao Z, Mei Z, Feng X, Feng R and Lu Q: Three-dimensional simulation of pulsatile blood low in human thoracic aorta. Acad J Sec Mil Med Univ 27: 867-875, 2006 (In Chinese).

This work is licensed under a Creative Commons Attribution-NonCommercial-NoDerivatives 4.0 International (CC BY-NC-ND 4.0) License. 